\title{
Critically ill patients with diabetes and Middle East respiratory syndrome: a multi- center observational study
}

Jesna Jose ${ }^{1,2}$, Hasan M. Al-Dorzi ${ }^{3}$ (D, Awad Al-Omari ${ }^{4}$, Yasser Mandourah ${ }^{5}$, Fahad Al-Hameed ${ }^{6}$, Musharaf Sadat ${ }^{3}$, Eman Al Qasim ${ }^{3}$, Basem Alraddadi ${ }^{7,8}$, Abdulrahman Al Harthy ${ }^{9}$, Ghaleb A. Al Mekhlafi ${ }^{10}$, Abdullah Almotairi ${ }^{11}$, Kasim Al Khatib ${ }^{12}$, Ahmed Abdulmomen ${ }^{13}$, Ismael Qushmaq ${ }^{14}$, Anees A. Sindi ${ }^{15}$, Ahmed Mady 9,16 , Othman Solaiman ${ }^{17}$, Rajaa Al-Raddadi ${ }^{18}$, Khalid Maghrabi ${ }^{17}$, Ahmed Ragab ${ }^{19}$, Ayman Kharaba ${ }^{20}$, Sarah Shalhoub ${ }^{21,22}$, Abdulsalam M. Al-Aithan ${ }^{23}$, Gajendra K. Vishwakarma², Atanu Bhattacharjee ${ }^{24}$, Yaseen M. Arabi ${ }^{3^{*}}$ (D) and The Saudi Critical Care Trials Group

\section{Abstract}

Background: Diabetes is a risk factor for infection with coronaviruses. This study describes the demographic, clinical data, and outcomes of critically ill patients with diabetes and Middle East Respiratory Syndrome (MERS).

Methods: This retrospective cohort study was conducted at 14 hospitals in Saudi Arabia (September 2012-January 2018). We compared the demographic characteristics, underlying medical conditions, presenting symptoms and signs, management and clinical course, and outcomes of critically ill patients with MERS who had diabetes compared to those with no diabetes. Multivariable logistic regression analysis was performed to determine if diabetes was an independent predictor of 90-day mortality.

Results: Of the 350 critically ill patients with MERS, 171 (48.9\%) had diabetes. Patients with diabetes were more likely to be older, and have comorbid conditions, compared to patients with no diabetes. They were more likely to present with respiratory failure requiring intubation, vasopressors, and corticosteroids. The median time to clearance of MERS-CoV RNA was similar (23 days (Q1, Q3: 17, 36) in patients with diabetes and 21.0 days $(\mathrm{Q} 1, \mathrm{Q} 3: 10,33)$ in patients with no diabetes). Mortality at 90 days was higher in patients with diabetes (78.9\% versus $54.7 \%, p<$ 0.0001). Multivariable regression analysis showed that diabetes was an independent risk factor for 90 -day mortality (odds ratio, 2.09; 95\% confidence interval, 1.18-3.72).

Conclusions: Half of the critically ill patients with MERS have diabetes; which is associated with more severe disease. Diabetes is an independent predictor of mortality among critically patients with MERS.

Keywords: Acute respiratory distress syndrome, Coronavirus, Diabetes, Middle East respiratory syndrome

\footnotetext{
*Correspondence: arabi@ngha.med.sa; yaseenarabi@yahoo.com

${ }^{3}$ Intensive Care Department, Ministry of National Guard Health Affairs, King Abdullah International Medical Research Center and King Saud Bin Abdulaziz University for Health Sciences, Riyadh, Saudi Arabia

Full list of author information is available at the end of the article
}

(C) The Author(s). 2021 Open Access This article is licensed under a Creative Commons Attribution 4.0 International License, which permits use, sharing, adaptation, distribution and reproduction in any medium or format, as long as you give appropriate credit to the original author(s) and the source, provide a link to the Creative Commons licence, and indicate if changes were made. The images or other third party material in this article are included in the article's Creative Commons licence, unless indicated otherwise in a credit line to the material. If material is not included in the article's Creative Commons licence and your intended use is not permitted by statutory regulation or exceeds the permitted use, you will need to obtain permission directly from the copyright holder. To view a copy of this licence, visit http://creativecommons.org/licenses/by/4.0/. The Creative Commons Public Domain Dedication waiver (http://creativecommons.org/publicdomain/zero/1.0/) applies to the data made available in this article, unless otherwise stated in a credit line to the data. 


\section{Background}

The Middle East respiratory syndrome coronavirus (MERS-CoV) is a novel zoonotic virus that can lead to severe acute respiratory infection (SARI) and lifethreatening multi-organ dysfunction. It was first isolated from a fatal case of pneumonia in Jeddah, Saudi Arabia in 2012 [1, 2]. Since then, community-acquired cases and clusters in healthcare settings have been reported mainly in Saudi Arabia [3, 4], but also other countries [5]. By the end of March 2020, the World Health Organization (WHO) reported 2553 confirmed cases in 27 countries (84.3\% of cases in Saudi Arabia) with a case fatality rate of $34.4 \%$ [6]. MERS clinical presentation ranges from asymptomatic infection to rapidly progressive severe respiratory failure with multi-organ failure [7, 8]. Symptoms usually manifest after an incubation period of 2-14 days, with fever, cough, and dyspnea [79]. Admission to the intensive care unit (ICU) is frequently needed [7, 8].

Most severe MERS cases have been reported in older adults with chronic comorbidities, including diabetes mellitus [2, 7, 9-12]. One cohort study found that among 47 MERS patients, 68\% had diabetes [7]. A casecontrol study demonstrated that diabetes was associated with an increased risk of MERS with an adjusted odds ratio [OR] of 6.99 (95\% confidence interval [CI], 1.8925.86) [11]. Diabetes has also been associated with increased mortality in MERS patients [9, 13]. In animal studies, diabetes was associated with a dysregulated immune response resulting in more severe and prolonged lung pathology following MERS-CoV infection [14].

Previous studies that evaluated diabetes in MERS had relatively small sample sizes, were mostly performed in single centers, and included a mix of critically and noncritically ill patients. We performed this study in a large cohort of critically ill patients with MERS, with the hypothesis that patients with diabetes and viral SARI would have a complicated course of illness and worse outcomes compared with patients with no diabetes. The objectives of this study are to describe the clinical presentation, management, and outcomes (including mortality and MERS-CoV RNA shedding) of the Middle East Respiratory Syndrome in critically ill patients with diabetes.

\section{Methods}

We followed the STROBE (STrengthening the Reporting of OBservational studies in Epidemiology) guidelines in reporting this study.

\section{Patients and settings}

This is a retrospective cohort study of adult ( $\geq 14$-yearold) patients with SARI due to MERS-CoV who were admitted to the ICUs of 14 referral hospitals in Saudi
Arabia between September 2012 and January 2018. The study was approved by the Institutional Review Boards of all participating centers. The characterization of this cohort has already been published earlier [15]. SARI was defined as an acute respiratory infection, with fever and cough onset within the preceding 10 days and clinical or radiologic lung involvement. The presence of MERS$\mathrm{CoV}$ was detected by real-time reverse-transcriptase polymerase chain reaction assay (rRT-PCR) performed on nasopharyngeal swabs or sputum samples in nonintubated patients and tracheal aspirates or bronchoalveolar lavage in intubated patients as recommended by the Saudi Arabian Ministry of Health. Confirmatory laboratory testing required a positive PCR on at least two specific genomic targets (upE and ORF1a) or a single positive target (upE) with sequencing of a second target (RdRpSeq or NSeq). In patients with suspected MERS and negative rRT-PCR, testing was repeated at the discretion of the treating teams. For infection control purposes, follow-up respiratory samples were collected approximately 1-2 times per week in MERS-CoV positive patients [16] to assess clearance of MERS-CoV RNA [15].

\section{Data collection}

Data were collected using the standardized International Severe Acute Respiratory and Emerging Infection Consortium (ISARIC) tool [17]. In this study, we included patients demographics, baseline characteristics, presenting symptoms, physiologic and laboratory parameters, and severity of illness on ICU admission assessed by the Sequential Organ Failure Assessment (SOFA) score [18]. We also described the management in the ICU, including the use of invasive and noninvasive ventilation, extracorporeal membrane oxygenation (ECMO), prone positioning, and selected medications.

The primary outcome was 90-day mortality. Other studied outcomes were mortality at 14 and 28 days and on ICU and hospital discharge and ICU and hospital length of stay (LOS). For patients who survived hospital discharge, the 90-day outcome was assessed by calling the patients. We also assessed the time to clearance of MERS-CoV RNA, which was defined as the time from the first performed rRT-PCR until the test was negative on two occasions, without a positive test afterward [15].

\section{Statistical analysis}

In this study, patients were divided into two groups based on the history of preexisting diabetes mellitus, as reported by patients. We compared patients with diabetes to patients with no diabetes using the Student ttest or the Mann-Whitney $U$ test for continuous variables based on normality assumption, and the chi-square test or Fisher's exact test for categorical variables. 
To examine the independent association of diabetes with 90-day mortality in MERS patients, we performed multivariable logistic regression analysis adjusting for certain variables selected based on their clinical relevance, excluding the ones which were in the exposurecausal pathway. The variables entered in the model were age, sex, asthma or chronic pulmonary disease, chronic neurological disease, immunosuppressant use before admission, body mass index (BMI), and SOFA score.

For the multivariable logistic regression analysis, 24\% $(84 / 350)$ of patients had missing data (BMI - 81/350, $23 \%$, age $-2 / 350,0.5 \%$, and SOFA score $-3 / 350,0.8 \%$ ). Hence missing data were handled using the multiple imputation technique with 50 imputations. Two imputation methods were considered to support the imputation technique: (I) "Predictive mean matching" and (II) "Impute then Transform" approach. The data set had an arbitrary missing data pattern and it was assumed that the missing data were missing at random, such that the probability of a missing observation may depend on observed values but not on unobserved values. Predictive mean matching was used to impute missing values for these variables. For the imputation of BMI, we used the "impute then transform" approach instead of imputing BMI directly, such that we imputed the height and weight assuming the imputation model was oblivious of the relation between these two variables [19]. We reported the results of multivariable regression analysis without imputation (Model I: Complete case analysis) and with imputation (Model II: Multiple imputation).

Kaplan-Meier curves for the time to MERS-CoV RNA clearance were constructed censoring by hospital discharge or at 90 days whichever occurred first. The logrank test was used to compare the median survival time between the groups. In addition, Kaplan-Meier curves for survival were also plotted and were censored at 90 days; the log-rank test was used to compare the time to survival between the groups. All statistical tests were two-sided with significance set at $\alpha<0.05$. All analyses were conducted using SAS version 9.4 (SAS Institute, Cary, NC).

\section{Results}

\section{Characteristics of patients}

During the study period, 350 patients with MERS SARI were admitted to the participating ICUs. Patients with diabetes constituted $48.9 \%$ of the cohort. Table 1 describes the characteristics and presenting symptoms of patients with diabetes and no diabetes. Compared to patients with no diabetes, those with diabetes were older (median age 61.0 years (Q1, Q3: 53.0, 72.0) versus median age 54.0 years (Q1, Q3: 35.0, 67.0), $p<0.0001)$ and more likely to have other comorbid conditions such as chronic renal disease (71 (41.5\%) versus 39 (21.8\%), $p<$ $0.0001)$ and cardiac disease (95 (55.6\%) versus 60 (40.5\%), $\mathrm{p}<0.0001)$. They were more likely to present with dyspnea and sputum production. The time from symptom onset to ICU admission was similar.

The laboratory findings are presented in Table 2. There were no differences in white blood cell and platelet counts between the two groups. Patients with diabetes had higher blood glucose (median $12.1 \mathrm{mmol} / \mathrm{L}$ (Q1,Q3: 9.9, 16.1) versus median $8.5 \mathrm{mmol} / \mathrm{L}(\mathrm{Q} 1, \mathrm{Q} 3$ : $6.5,11.6$ ), $\mathrm{p}<0.0001$ ), blood urea nitrogen (median 12.0 $\mathrm{mmol} / \mathrm{L}(\mathrm{Q} 1, \mathrm{Q} 3: 7.3,20.8)$ versus median $9.1 \mathrm{mmol} / \mathrm{L}$ (Q1,Q3: 4.1, 16.9), $p=0.0002$ ) and creatinine (median 141.4 mmol/L (Q1,Q3: 91.0, 327.0) versus median 114.9 $\mathrm{mmol} / \mathrm{L}$ (Q1,Q3: 67.0, 217.0), $p=0.0004)$.

\section{Management in the ICU}

Table 3 shows the management interventions performed during the ICU stay. More patients with diabetes were treated with non-invasive ventilation and with invasive mechanical ventilation $(89.5 \%$ versus $81.6 \%, p=0.04)$ than non-diabetics. The time from symptom onset to intubation was similar. In comparison to patients with no diabetes, there was more use of nitric oxide in patients with diabetes $(28(16.4 \%)$ versus $16(8.9), \mathrm{p}=0.04$, but less use of ECMO (6 (3.5\%) versus $16(8.9 \%), \mathrm{p}=0.04)$.

For other organ support, more patients with diabetes had shock requiring vasopressors compared to those with no diabetes $(86.0 \%$ versus $72.1 \%, p=0.002)$. Corticosteroids were given more commonly in patients with diabetes $(58.5 \%$ versus $41.9 \%, \mathrm{p}=0.002)$. Renal replacement therapy was provided more often in patients with diabetes $(60.2 \%$ versus $39.7 \%, p=0.0001)$. More patients with diabetes received ribavirin and interferon $(40.9 \%$ versus $26.3 \%, p=0.02$ ).

\section{Outcomes of patients}

The mortality at 90 days was higher in patients with diabetes $(78.9 \%$ versus $54.7 \%, \mathrm{p}<0.0001)$ (Table 3$)$. On multivariable logistic regression analysis, in both the models (I and II) diabetes was associated with increased mortality (OR, 2.09; 95\% CI, 1.18-3.72). Other predictors of mortality were age (OR per 1-year increment, 1.04; 95\% CI, 1.02-1.06), female gender (OR 1.68; 95\% CI, 1.06-2.67), SOFA (OR per 1-point increment 1.20; 95\% CI, 1.14-1.26) (Table 4).

ICU LOS was longer for patients with diabetes (Table 3). The time to clearance of MERS-CoV RNA was similar in both groups (23 days (Q1, Q3: 17, 36) in patients with diabetes and 21.0 days (Q1, Q3: 10, 33) in patients with no diabetes). Figure 1 demonstrates the Kaplan Meir curves for time-to-clearance of MERS-CoV rRT-PCR and shows no difference between patients with diabetes and no diabetes. 
Table 1 Baseline characteristics of patients with diabetes and Middle East Respiratory Syndrome (MERS) compared to patients with no diabetes and MERS

\begin{tabular}{|c|c|c|c|}
\hline Variables & Diabetes $N=171$ & No Diabetes $N=179$ & $P$-value \\
\hline Age (year), median (Q1, Q3) & $61.0(53.0,72.0)$ & $54.0(35.0,67.0)$ & $<0.0001$ \\
\hline $\mathrm{BMI}\left(\mathrm{Kg} / \mathrm{m}^{2}\right)$, median $(\mathrm{Q} 1, \mathrm{Q} 3)$ & $29.3(24.6,33.3)$ & $28.3(24.1,33.0)$ & 0.31 \\
\hline Male sex - no. (\%) & $114(66.7)$ & $127(70.9)$ & 0.39 \\
\hline Healthcare worker - no. (\%) & $4(2.3)$ & $28(15.6)$ & $<0.0001$ \\
\hline Community-acquired - no. (\%) & $102(59.6)$ & $83(46.4)$ & \\
\hline Healthcare-associated (Non-healthcare worker) - no. (\%) & $65(38.0)$ & $68(38.0)$ & \\
\hline Days from the onset of symptoms to the emergency room, median (Q1, Q3) & $5.0(3.0,8.0)$ & $4.0(2.0,7.0)$ & 0.30 \\
\hline Days from symptom onset to ICU admission, median (Q1, Q3) & $7.0(4.0,10.5)$ & $7.0(4.0,11.0)$ & 0.66 \\
\hline Days from symptom onset to intubation, median (Q1, Q3) & $8.0(5.0,12.0)$ & $8.0(5.0,13.0)$ & 0.37 \\
\hline \multicolumn{4}{|l|}{ Presenting symptoms - no. (\%) } \\
\hline \multicolumn{4}{|l|}{ Lower respiratory } \\
\hline Dyspnea & $136(79.5)$ & $123(68.7)$ & 0.02 \\
\hline Cough & $122(71.3)$ & $117(65.4)$ & 0.23 \\
\hline With sputum & $75(43.9)$ & $58(32.4)$ & 0.03 \\
\hline With bloody sputum & $11(6.4)$ & $18(10.1)$ & 0.22 \\
\hline Chest pain & $36(21.1)$ & $32(17.9)$ & 0.45 \\
\hline Wheezing & $10(5.8)$ & $9(5.0)$ & 0.74 \\
\hline \multicolumn{4}{|l|}{ Upper respiratory } \\
\hline Earache & $2(1.2)$ & $1(0.6)$ & $0.62 \wedge$ \\
\hline Rhinorrhea & $6(3.5)$ & $11(6.1)$ & 0.25 \\
\hline Sore throat & $23(13.5)$ & $24(13.4)$ & 0.99 \\
\hline \multicolumn{4}{|l|}{ Systemic symptoms } \\
\hline Fever (temperature $>38^{\circ} \mathrm{C}$ ) & $130(76.0)$ & $131(73.2)$ & 0.54 \\
\hline Myalgia or arthralgia & $32(18.7)$ & $34(19.0)$ & 0.95 \\
\hline Headache & $14(8.2)$ & $21(11.7)$ & 0.27 \\
\hline Fatigue & $66(38.6)$ & $55(30.7)$ & 0.12 \\
\hline Abdominal pain & $22(12.9)$ & $25(14.0)$ & 0.76 \\
\hline Lymphadenopathy & $1(0.6)$ & $2(1.1)$ & $>0.99 \wedge$ \\
\hline Diarrhea & $20(11.7)$ & $18(10.1)$ & 0.62 \\
\hline Vomiting/nausea & $28(16.4)$ & $30(16.8)$ & 0.92 \\
\hline Altered consciousness/ confusion & $44(25.7)$ & $30(16.8)$ & 0.04 \\
\hline Seizures & $2(1.2)$ & $2(1.1)$ & $>0.99 \wedge$ \\
\hline \multicolumn{4}{|l|}{ Other comorbidities - no. (\%) } \\
\hline Chronic pulmonary disease (including asthma) & $22(12.9)$ & $24(13.4)$ & 0.88 \\
\hline Liver disease & $12(7.0)$ & $10(5.6)$ & 0.58 \\
\hline Chronic renal disease & $71(41.5)$ & $39(21.8)$ & $<0.0001$ \\
\hline Chronic cardiac disease & $95(55.6)$ & $43(24.0)$ & $<0.0001$ \\
\hline Chronic neurological disease & $22(12.9)$ & $16(8.9)$ & 0.24 \\
\hline $\mathrm{BMI}>30\left(\mathrm{Kg} / \mathrm{m}^{2}\right)$ & $55(45.5)$ & $60(40.5)$ & 0.42 \\
\hline Rheumatologic disease & $2(1.2)$ & $5(2.8)$ & $0.45 \wedge$ \\
\hline Any malignancy including leukemia, lymphoma, or solid tumors & $14(8.2)$ & $20(11.2)$ & 0.35 \\
\hline Immunosuppressant use before admission & $6(3.5)$ & $15(8.4)$ & 0.06 \\
\hline SOFA score on ICU day 1, median (Q1, Q3) & $9.0(6.0,12.0)$ & $8.0(5.0,11.0)$ & 0.02 \\
\hline
\end{tabular}

BMI Body mass index, ICU intensive care unit, Q1 first quartile, Q3 third quartile, SOFA Sequential Organ Failure Assessment

The denominator of the percentage is the total number of subjects in the treatment group. For continuous variables, Mann-Whitney $\mathrm{U}$ test was used to calculate the P-value. For categorical variables, Chi-square test was used to calculate the $P$-value unless otherwise noted. $\wedge$ Fisher's exact test was used to calculate P-value 


\section{Discussion}

Our study demonstrates that patients with diabetes constituted around half of the critically ill patients with MERS; MERS patients with diabetes presented with dyspnea and sputum production and were more likely to have respiratory failure requiring mechanical ventilation than those with no diabetes; and diabetes was an independent predictor of mortality in MERS. Viral shedding duration was similar in patients with diabetes and no diabetes.

Diabetes is a global health problem and leads to significant complications that increase the risk of morbidity and development of critical illness. Saudi Arabia is among the countries with high prevalence rates $(>30 \%)$ [20]. This may partly explain the high prevalence of diabetes in our cohort of critically ill MERS patients. In a Korean cohort of 186 patients with confirmed MERS patients, diabetes was present in $18.8 \%$ [9]. In our study, patients with diabetes presented with more severe respiratory symptoms and hypoxia, required mechanical ventilation more frequently, and were given nitric oxide as rescue therapy more often. They also required vasopressors more often. These patients were more likely to receive ribavirin and interferon (alpha or beta-1a) alone or in combination; these antivirals have not been associated with improved outcomes in MERS [21]. Recently, the MIRACLE trial demonstrated a reduction in mortality with the combination of lopinavir-ritonavir and interferon beta-1b; but none of patients in this cohort had received this combination [22].

Diabetes is associated with reduced neutrophil chemotaxis after stimulation [23] and blunted inflammatory response to endotoxemia [24]. These abnormalities are thought to be the reasons why diabetics have an increased risk of various infections [25]. For viral infections, diabetes has been associated with increased risk for hospitalization after H1N1 infection [26], ICU admission [26], and death [27]. Comorbidities, including diabetes, have been associated with increased mortality in MERS patients [28]. In a small cohort from two hospitals in Saudi Arabia, diabetes was present in $10.5 \%$ of survivors and $70.0 \%$ of non-survivors $(p=0.002)$ [29]. A study that evaluated MERS cases during the Korean outbreak found that diabetes was a risk factor for mortality on multivariate analysis (OR, 2.47; 95\% CI, 1.06-5.72) [9]. Analysis of 1743 MERS cases found that patients with comorbidity (diabetes mellitus, cardiovascular disease, renal disease, or pulmonary disease) had higher mortality risk (adjusted hazard ratio, of 3.7; 95\% CI, 2.65.7) [13]. In Severe Acute Respiratory Syndrome (SARS), diabetes (OR, 3.0; 95\% CI, 1.4-6.3) and fasting blood glucose $\geq 7.0 \mathrm{mmol} / \mathrm{L}(\mathrm{OR}, 3.3 ; 95 \%$, CI 1.4-7.7) were

Table 2 Physiological parameters on day 1 of admission to ICU in patients with diabetes and Middle East Respiratory Syndrome (MERS) compared to patients with no diabetes and MERS

\begin{tabular}{|c|c|c|c|}
\hline Variables & $\begin{array}{l}\text { Diabetes } \\
N=179\end{array}$ & $\begin{array}{l}\text { No Diabetes } \\
N=171\end{array}$ & $P$-value \\
\hline \multicolumn{4}{|c|}{ Respiratory parameters on ICU day 1, median (Q1, Q3) } \\
\hline $\mathrm{PaO}_{2}(\mathrm{mmHg})$ & $65.1(56.0,79.0)$ & $71.0(60.2,86.4)$ & 0.01 \\
\hline $\mathrm{SaO}_{2}(\%)$ & $92.0(87.0,95.0)$ & $93.5(90.0,95.0)$ & 0.004 \\
\hline $\mathrm{FiO}_{2}$ & $0.7(0.45,1.0)$ & $0.6(0.45,1.00)$ & 0.24 \\
\hline $\mathrm{PaO}_{2} / \mathrm{FiO}_{2}$ ratio & $98.0(64.0,160.0)$ & $122.6(73.4,187.5)$ & 0.02 \\
\hline \multicolumn{4}{|c|}{ Extrapulmonary parameters on ICU day 1, median (Q1, Q3) } \\
\hline Mean arterial pressure (mmHg) & $70.0(61.0,83.0)$ & $70.0(60.0,80.0)$ & 0.72 \\
\hline Leukocyte $\left(\times 10^{9} / \mathrm{L}\right)$ & $7.90(4.50,11.60)$ & $6.80(4.20,11.20)$ & 0.31 \\
\hline Hemoglobin (g/dL) & $10.4(9.0,12.50)$ & $11.0(8.5,13.0)$ & 0.48 \\
\hline Hematocrit & $33.0(28.55,38.50)$ & $35.0(28.0,40.0)$ & 0.24 \\
\hline Platelets $\left(\times 10^{9} / \mathrm{L}\right)$ & $188.0(117.0,253.0)$ & $168.5(113.0,253.0)$ & 0.32 \\
\hline Glucose (mmol/L) & $12.1(9.9,16.1)$ & $8.5(6.5,11.6)$ & $<0.0001$ \\
\hline Blood urea nitrogen $(\mathrm{mmol} / \mathrm{L})$ & $12.0(7.3,20.8)$ & $9.1(4.1,16.9)$ & 0.0002 \\
\hline Creatinine $(\mu \mathrm{mol} / \mathrm{L})$ & $141.4(91.0,327.0)$ & $114.9(67.0,217.0)$ & 0.0004 \\
\hline Bilirubin ( $\mu \mathrm{mol} / \mathrm{L})$ & $12.3(7.8,23.7)$ & $12.0(7.8,22.9)$ & 0.86 \\
\hline
\end{tabular}

$\mathrm{PaO} 2$ partial pressure of oxygen, $\mathrm{SaO} 2$ Oxygen saturation, $\mathrm{FiO} 2$ Fraction of inspired oxygen, $\mathrm{PaO} 2 \mathrm{FiO} 2$ ratio, the ratio of the partial pressure of oxygen to the fraction of inspired oxygen, $A L T$ alanine aminotransferase, AST aspartate transaminase, Q1 first quartile, Q3 third quartile

Data on variables were not available for some patients; the number of patients with missing data in the Diabetes group and the No diabetes group, respectively were as follows: $\mathrm{PaO} 2: 5$ patients and 3 patients, SaO2: 3 patients and 3 patients, FiO2: 8 patients and 17 patients, $\mathrm{PaO} 2$ : FiO2 ratio: 9 patients and 19 patients, MAP: 5 patients and 5 patients, Leukocyte: 5 patients and 9 patients, Hemoglobin: 5 patients and 10 patients, Hematocrit:7 patients, and 9 patients, Platelets: 6 patients and 5 patients, Glucose: 23 patients and 26 patients, Blood urea: 8 patients and 9 patients, Creatinine: 4 patients and 2 patients, Bilirubin level: 22 patients and 23 patients 
Table 3 Main interventions and outcomes in patients with diabetes and Middle East Respiratory Syndrome (MERS) compared to patients with no diabetes and MERS

\begin{tabular}{|c|c|c|c|}
\hline Variables & $\begin{array}{l}\text { Diabetes } \\
N=171\end{array}$ & $\begin{array}{l}\text { No Diabetes } \\
N=179\end{array}$ & $P$-value \\
\hline \multicolumn{4}{|l|}{ Interventions } \\
\hline Non-invasive positive pressure ventilation - no. (\%) & $64(37.4)$ & $43(24.0)$ & 0.007 \\
\hline Invasive ventilation - no. (\%) & $153(89.5)$ & $146(81.6)$ & 0.04 \\
\hline Duration, median (Q1, Q3) & $9.5(4.0,17.0)$ & $9.0(4.0,16.0)$ & 0.68 \\
\hline Neuromuscular blockade - no. (\%) & $55(32.2)$ & $78(43.6)$ & 0.03 \\
\hline High-frequency oscillation ventilation - no. (\%) & $16(9.4)$ & $10(5.6)$ & 0.18 \\
\hline ECMO - no. (\%) & $6(3.5)$ & $16(8.9)$ & 0.04 \\
\hline Nitric oxide - no. (\%) & $28(16.4)$ & $16(8.9)$ & 0.04 \\
\hline Prone positioning - no. (\%) & $14(8.2)$ & $19(10.6)$ & 0.44 \\
\hline Duration, median (Q1, Q3) & $3.0(2.0,3.0)$ & $3.0(2.0,3.0)$ & 0.97 \\
\hline Any oxygen rescue therapy - no. (\%) & $73(42.7)$ & $84(46.9)$ & 0.43 \\
\hline Vasopressors - no. (\%) & $147(86.0)$ & $129(72.1)$ & 0.002 \\
\hline Duration, median (Q1, Q3) & $6.5(4.0,13.0)$ & $6.0(3.0,14.0)$ & 0.83 \\
\hline Blood transfusion - no. (\%) & $59(34.5)$ & $58(32.4)$ & 0.68 \\
\hline \multicolumn{4}{|l|}{ Antivirals - no. (\%) } \\
\hline Both interferon and ribavirin - no. (\%) & $70(40.9)$ & $47(26.3)$ & $0.02 \wedge$ \\
\hline Interferon only - no. (\%) & $4(2.3)$ & $5(2.8)$ & \\
\hline Ribavirin only - no. (\%) & $10(5.8)$ & $8(4.5)$ & \\
\hline Oseltamivir - no. (\%) & $89(52.0)$ & $107(59.8)$ & 0.15 \\
\hline Corticosteroids - no. (\%) & $100(58.5)$ & $75(41.9)$ & 0.002 \\
\hline Renal replacement therapy - no. (\%) & $103(60.2)$ & $71(39.7)$ & 0.0001 \\
\hline Duration, median (Q1, Q3) & $8.0(4.0,14.0)$ & $8.0(3.0,14.0)$ & 0.92 \\
\hline Intravenous immunoglobins - no. (\%) & $9(5.3)$ & $15(8.4)$ & 0.25 \\
\hline Tracheostomy - no (\%) & $5(2.9)$ & $9(5.0)$ & 0.32 \\
\hline \multicolumn{4}{|l|}{ Outcomes } \\
\hline ICU mortality - no. (\%) & $133(77.8)$ & $95(53.1)$ & $<0.0001$ \\
\hline Hospital mortality - no. (\%) & $136(79.5)$ & $102(57.0)$ & $<0.0001$ \\
\hline 90-day mortality - no. (\%) & $135(78.9)$ & $98(54.7)$ & $<0.0001$ \\
\hline 28-day mortality - no. (\%) & $127(74.3)$ & $90(50.3)$ & $<0.0001$ \\
\hline 14-day mortality - no. (\%) & $89(52.0)$ & $76(42.5)$ & 0.07 \\
\hline ICU length of stay (days), median (Q1, Q3) & $11.0(6.0,19.0)$ & $8.0(5.0,17.0)$ & 0.05 \\
\hline Hospital length of stay (days), median (Q1, Q3) & $18.0(10.0,33.0)$ & $20.0(10.0,37.0)$ & 0.63 \\
\hline
\end{tabular}

ECMO extracorporeal membrane oxygenation, ICU Intensive care unit. The denominator of the percentage is the total number of subjects in the group

independent predictors of death [30]. Studies on the association of diabetes with disease severity and outcome in COVID-19 have yielded mixed results [31-36]. In a meta-analysis, the risk of severe COVID-19 was not significantly increased in patients with diabetes (OR, 2.07; 95\% CI, 0.89-4.82) [36]. Other studies found no association between diabetes and morality [32, 35].

It remains unclear how diabetes may contribute to increased disease severity and mortality in people infected with MERS-CoV. In a mouse model of MERS-CoV infection, diabetic mice had a prolonged phase of severe disease and delayed recovery compared to non-diabetic mice [14]. This was associated with delayed inflammation which lasted through 21 days after infection [14]. Diabetic mice exhibited fewer inflammatory monocyte/ macrophages and $\mathrm{CD} 4+\mathrm{T}$ cells and lower levels of TNF-a, IL-6, and IL-12b [14]. This may explain the findings of severe MERS in patients with diabetes.

Viral shedding was relatively prolonged in our MERS patients. However, the time to clearance of MERS-CoV RNA was similar in patients with diabetes and no diabetes. Prolonged shedding has been reported in MERS 
Table 4 Multivariable model to examine whether diabetes is an independent predictor of 90-day mortality in patients with Middle East Respiratory Syndrome (MERS). We adjusted for age, sex, asthma or chronic pulmonary disease, chronic neurological disease, immunosuppressant use before admission, body mass index (BMI), and SOFA score. Model I: Complete case analysis with no imputation (participants with any missing data are excluded). Model II: Multiple imputation (participants with missing data identified and replaced)

\begin{tabular}{|c|c|c|c|c|}
\hline \multirow[t]{2}{*}{ Variables } & \multicolumn{2}{|l|}{ Model I $(N=266)$} & \multicolumn{2}{|c|}{ Model II $(N=350)$} \\
\hline & OR $(95 \% \mathrm{Cl})$ & $P$-value & OR $(95 \% \mathrm{Cl})$ & $P$-value \\
\hline Diabetes & $2.09(1.18,3.72)$ & 0.005 & $2.13(1.15,3.95)$ & 0.02 \\
\hline SOFA (per one-unit increase) & $1.20(1.14,1.26)$ & $<0.0001$ & $1.17(1.12,1.23)$ & $<0.0001$ \\
\hline Female sex & $1.68(1.06,2.67)$ & 0.02 & $1.74(1.09,2.79)$ & 0.02 \\
\hline Age (per one-year increase) & $1.04(1.02,1.06)$ & 0.0002 & $1.04(1.02,1.06)$ & $<0.0001$ \\
\hline Chronic neurological disease & $3.07(0.80,11.81)$ & 0.07 & $3.40(1.04,11.14)$ & 0.04 \\
\hline BMI (kg/m²) (per one-unit increase) & $0.97(0.90,1.03)$ & 0.23 & $0.96(0.91,1.02)$ & 0.21 \\
\hline Immunosuppressant use before admission & $1.24(0.29,5.26)$ & 0.74 & $1.13(0.35,3.64)$ & 0.84 \\
\hline Asthma or chronic pulmonary disease & $1.20(0.66,2.20)$ & 0.51 & $1.04(0.57,1.91)$ & 0.90 \\
\hline
\end{tabular}

OR Odds Ratio, CI Confidence Interval, BMI body mass index, SOFA Sequential Organ Failure Assessment

patients in other studies [37], and has been associated with corticosteroid use [38]. Corticosteroids were used more commonly in patients with diabetes in the current study.

The findings of this study should be interpreted in light of its strengths and weaknesses. The strengths include that it is the largest cohort of critically ill patients with MERS. The limitations are related to the nature of the database and include diabetes diagnosis by history and absence of data on glycemic measures, such as type of diabetes, hemoglobin A1c, glucose control during hospitalization, and prior or current diabetes medications. In addition, glucose levels in patients with no diabetes were elevated, suggesting that some patients had stress hyperglycemia or undiagnosed diabetes. This may affect the associations between diabetes and various outcomes. Given the high prevalence of diabetes in Saudi Arabia, the results of our study may not be generalizable to populations of lower diabetes prevalence.

\section{Conclusion}

Diabetes was highly prevalent in a cohort of critically ill patients with MERS. Patients with diabetes had more severe illness. Diabetes was an independent predictor of mortality.

Ethics approval and consent to participants The study was approved by the Ministry of National Guard Health

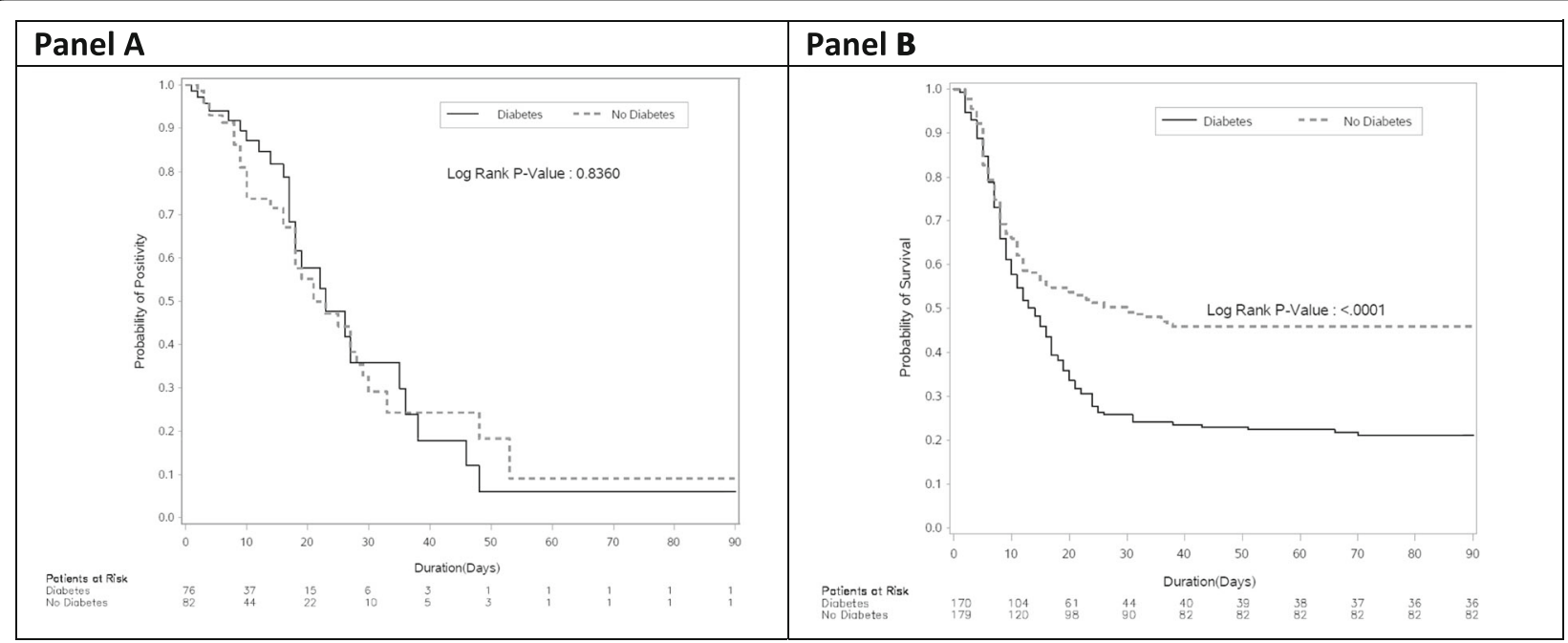

Fig. 1 Panel a: Time-to-clearance of the Middle East respiratory syndrome coronavirus (MERS-CoV) RNA among patients with diabetes and no diabetes. Time to clearance was defined as the time taken from the date of ICU admission to having two negative RT-PCR tests not followed by positive test. Log-rank test is used to calculate the $P$-value. Panel b: Kaplan Meir curves for survival among patients with diabetes and no diabetes and Middle East respiratory syndrome (MERS) 
Affairs Institutional Review Board (IRB- RC14-025-R) and by the IRBs of all participating sites (Table S2: Supplement). Informed consent was waived by the IRB because of the retrospective and observational nature of the study.

\section{Supplementary Information}

The online version contains supplementary material available at https://doi. org/10.1186/s12879-021-05771-y.

\section{Additional file 1.}

\section{Acknowledgments}

We would like to thank the International Severe Acute Respiratory and Emerging Infection Consortium (ISARIC) for their support in the database construction.

\section{Authors' contributions}

JJ and YMA: Conception and design, data acquisition, analytical plan, interpretation of data for the work, drafting of the manuscript, critical revision of the manuscript for important intellectual content, approval of the final version to be published, and agreement to be accountable for all aspects of the work. HMD, AO, YM, FH, MS, EQ, BAR, ARH, GAM, AA, KK, AAM, IQ, AAS, AM, OS, RR, KM, AR, AK, SS, AMA: Data acquisition, critical revision of the manuscript for important intellectual content, approval of the final version to be published, and agreement to be accountable for all aspects of the work. GKV and AB: Conception and design, analytical plan, data analysis, critical revision of the manuscript for important intellectual content, approval of the final version to be published, and agreement to be accountable for all aspects of the work.

\section{Funding}

This research did not receive any specific grant from funding agencies in the public, commercial, or not-for-profit sectors.

\section{Availability of data and materials}

The dataset(s) supporting the conclusions of this article will be made available on the approval of the PI and according to the rules of King Abdullah International Medical Research Center (KAIMRC).

\section{Consent for publication}

All the authors have read the final manuscript and approved its submission.

\section{Competing interests}

Yaseen Arabi provided nonpaid consultations on therapeutics for MERS for Gilead Sciences and SAB Biotherapeutics and he is a Board Member of the International Severe Acute Respiratory and Emerging Infection Consortium (ISARIC). He is the Lead-Co Chair of the Think-20 Saudi Arabia (T20) Taskforce for COVID-19. Other authors declared that they have no competing interests.

\section{Author details}

${ }^{1}$ Department of Biostatistics and Bioinformatics, King Abdullah International Medical Research Center, Riyadh, Saudi Arabia. ${ }^{2}$ Department of Mathematics \& Computing, Indian Institute of Technology (ISM), Dhanbad, Jharkhand 826004, India. ${ }^{3}$ Intensive Care Department, Ministry of National Guard Health Affairs, King Abdullah International Medical Research Center and King Saud Bin Abdulaziz University for Health Sciences, Riyadh, Saudi Arabia. ${ }^{4}$ Department of Intensive Care, College of Medicine, Alfaisal University, Dr Sulaiman Al-Habib Group Hospitals, Riyadh, Saudi Arabia. ${ }^{5}$ Military Medical Services, Ministry of Defense, Prince Sultan Military Medical City, Riyadh, Saudi Arabia. ${ }^{6}$ Department of Intensive Care, College of Medicine, King Saud bin Abdulaziz University for Health Sciences, King Abdullah International Medical Research Center, King Abdulaziz Medical City, Jeddah, Saudi Arabia. ${ }^{7}$ Department of Medicine, King Faisal Specialist Hospital and Research Center, Jeddah, Saudi Arabia. ${ }^{8}$ Department of Medicine, University of Jeddah, Jeddah, Saudi Arabia. ${ }^{9}$ Intensive Care Department, King Saud Medical City, Riyadh, Saudi Arabia. ${ }^{10}$ Department of Intensive Care Services, Prince Sultan Military Medical City, Riyadh, Saudi Arabia. ${ }^{11}$ Department of Critical Care
Medicine, King Fahad Medical City, Riyadh, Saudi Arabia. ${ }^{12}$ Intensive Care Department, Al-Noor Specialist Hospital, Makkah, Saudi Arabia. ${ }^{13}$ Department of Critical Care Medicine, King Saud University, Riyadh, Saudi Arabia. ${ }^{14}$ Section of Critical Care Medicine, Department of Medicine, King Faisal Specialist Hospital and Research Center, Jeddah, Saudi Arabia. ${ }^{15}$ Department of Anesthesia and Critical Care, Faculty of Medicine, King Abdulaziz University, Jeddah, Saudi Arabia. ${ }^{16}$ Tanta University Hospitals, Tanta, Egypt. ${ }^{17}$ Intensive Care Department, King Faisal Specialist Hospital and Research Center, Riyadh, Saudi Arabia. ${ }^{18}$ Department of Community Medicine, Faculty of Medicine, King Abdulaziz University, Jeddah, Saudi Arabia. ${ }^{19}$ Intensive Care Department, King Fahd Hospital, Jeddah, Saudi Arabia. ${ }^{20}$ Department of Critical Care, King Fahad Hospital, Ohoud Hospital, Al-Madinah, Saudi Arabia. ${ }^{21}$ Department of Medicine, Division of Infectious Diseases, University of Western Ontario, London, Canada. ${ }^{22}$ King Fahad Armed Forces Hospital, Jeddah, Saudi Arabia. ${ }^{23}$ Department of Medicine, Critical Care Division, King Abdulaziz Hospital, Al Ahsa, Saudi Arabia. ${ }^{24}$ Homi Bhaba National Institute, Section of Biostatistics, Centre for Cancer Epidemiology, Tata Memorial Centre, Navi Mumbai, India.

Received: 12 August 2020 Accepted: 6 January 2021

Published online: 19 January 2021

\section{References}

1. Zaki AM, van Boheemen S, Bestebroer TM, Osterhaus AD, Fouchier RA Isolation of a novel coronavirus from a man with pneumonia in Saudi Arabia. N Engl J Med. 2012;367(19):1814-20.

2. Arabi YM, Balkhy HH, Hayden FG, Bouchama A, Luke T, Baillie JK, Al-Omari A, Hajeer AH, Senga M, Denison MR, et al. Middle East respiratory syndrome. N Engl J Med. 2017;376(6):584-94.

3. Assiri A, McGeer A, Perl TM, Price CS, Al Rabeeah AA, Cummings DA, Alabdullatif ZN, Assad M, Almulhim A, Makhdoom H, et al. Hospital outbreak of Middle East respiratory syndrome coronavirus. N Engl J Med. 2013;369(5): 407-16

4. Oboho IK, Tomczyk SM, Al-Asmari AM, Banjar AA, Al-Mugti H, Aloraini MS, Alkhaldi KZ, Almohammadi EL, Alraddadi BM, Gerber Sl, et al. 2014 MERSCoV outbreak in Jeddah--a link to health care facilities. N Engl J Med. 2015; 372(9):846-54

5. Cho S, Kang J, Ha Y, Park G, Lee J, Ko J, Lee J, Kim J, Kang C, Jo I. MERS-CoV outbreak following a single patient exposure in an emergency room in South Korea: an epidemiological outbreak study. Lancet (London, England). 2016;388(10048):994

6. Cai Y, Yu SQ, Postnikova EN, Mazur S, Bernbaum JG, Burk R, Zhang T, Radoshitzky SR, Muller MA, Jordan I, et al. CD26/DPP4 cell-surface expression in bat cells correlates with bat cell susceptibility to Middle East respiratory syndrome coronavirus (MERS-CoV) infection and evolution of persistent infection. PLoS One. 2014;9(11):e112060.

7. Assiri A, Al-Tawfiq J, Al-Rabeeah A, Al-Rabiah F, Al-Hajjar S, Al-Barrak A, Flemban H, Al-Nassir W, Balkhy H, Al-Hakeem R. Epidemiological, demographic, and clinical characteristics of 47 cases of Middle East respiratory syndrome coronavirus disease from Saudi Arabia: a descriptive study. Lancet Infect Dis. 2013;13(9):752.

8. Saad M, Omrani A, Baig K, Bahloul A, Elzein F, Matin M, Selim M, Al Mutairi M, Al Nakhli D, Al Aidaroos A. Clinical aspects and outcomes of 70 patients with Middle East respiratory syndrome coronavirus infection: a single-center experience in Saudi Arabia. Int J Infect Dis. 2014;29:301.

9. Choi WS, Kang C-I, Kim Y, Choi J-P, Joh JS, Shin H-S, Kim G, Peck KR, Chung DR, Kim HO. Clinical presentation and outcomes of Middle East respiratory syndrome in the Republic of Korea. Infect Chemother. 2016; 48(2):118.

10. Al-Tawfiq JA, Hinedi K, Ghandour J, Khairalla H, Musleh S, Ujayli A, Memish ZA. Middle East respiratory syndrome coronavirus: a case-control study of hospitalized patients. Clin Infect Dis. 2014;59(2):160-5.

11. Alraddadi BM, Watson JT, Almarashi A, Abedi GR, Turkistani A, Sadran M, Housa A, Almazroa MA, Alraihan N, Banjar A. Risk factors for primary Middle East respiratory syndrome coronavirus illness in humans, Saudi Arabia, 2014 Emerg Infect Dis. 2016;22(1):49.

12. Alqahtani F, Aleanizy F, Mohamed RAEH, Alanazi M, Mohamed N, Alrasheed M, Abanmy N, Alhawassi T. Prevalence of comorbidities in cases of Middle East respiratory syndrome coronavirus: a retrospective study. Epidemiol Infect. 2019;147:1-5 
13. Yang Y-M, Hsu C-Y, Lai C-C, Yen M-F, Wikramaratna PS, Chen H-H, Wang T-H. Impact of comorbidity on fatality rate of patients with Middle East respiratory syndrome. Sci Rep. 2017;7:11307.

14. Kulcsar KA, Coleman CM, Beck SE, Frieman MB. Comorbid diabetes results in immune dysregulation and enhanced disease severity following MERS-CoV infection. JCl insight. 2019:4(20)

15. Arabi YM, Al-Omari A, Mandourah Y, Al-Hameed F, Sindi AA, Alraddadi B, Shalhoub S, Almotairi A, Al Khatib K, Abdulmomen A. Critically ill patients with the Middle East respiratory syndrome: a multicenter retrospective cohort study. Crit Care Med. 2017:45(10):1683-95.

16. Mawatari $H$, Yoneda $M$, Fujita $K$, Nozaki $Y$, Shinohara $Y$, Sasaki $H$, lida $H$, Takahashi $\mathrm{H}$, Inamori M, Abe $Y$, et al. Association between phospholipids and free cholesterol in high-density lipoprotein and the response to hepatitis C treatment in Japanese with genotype 1b. J Viral Hepat. 2010; 17(12):859-65.

17. Chowell G, Blumberg S, Simonsen L, Miller MA, Viboud C. Synthesizing data and models for the spread of MERS-CoV, 2013: key role of index cases and hospital transmission. Epidemics. 2014;9:40-51.

18. Vincent J, Moreno R, Takala J, Willatts S, De Mendonça A, Bruining H, Reinhart C, Suter P, Thijs L. The SOFA (Sepsis-related Organ Failure Assessment) score to describe organ dysfunction/failure. On behalf of the Working Group on Sepsis-Related Problems of the European Society of Intensive Care Medicine. Intensive Care Med. 1996;22(7):707.

19. Von Hippel PT. How to impute interactions, squares and ther transformed variables. Sociol Methodol. 2009;39(1):265-91.

20. Meo S, Usmani A, Qalbani E. Prevalence of type 2 diabetes in the Arab world: impact of GDP and energy consumption. Eur Rev Med Pharmacol Sci. 2017;21(6):1303.

21. Arabi Y, Shalhoub S, Mandourah Y, Al-Hameed F, Al-Omari A, Al Qasim E, Jose J, Alraddadi B, Almotairi A, Al Khatib K. Ribavirin and interferon therapy for critically ill patients with Middle East respiratory syndrome: a multicenter observational study. Clin Infect Dis. 2019.

22. Arabi YM, Asiri AY, Assiri AM, Balkhy HH, Al Bshabshe A, Al Jeraisy M, Mandourah Y, Azzam MHA, Bin Eshaq AM, Al Johani S, et al. Interferon Beta$1 \mathrm{~b}$ and Lopinavir-ritonavir for Middle East respiratory syndrome. N Engl J Med. 2020;383(17):1645-56.

23. Delamaire M, Maugendre D, Moreno M, Le Goff MC, Allannic H, Genetet B. Impaired leucocyte functions in diabetic patients. Diabet Med. 1997;14(1): 29-34.

24. Andreasen AS, Pedersen-Skovsgaard T, Berg RM, Svendsen KD, FeldtRasmussen B, Pedersen BK, Moller K. Type 2 diabetes mellitus is associated with impaired cytokine response and adhesion molecule expression in human endotoxemia. Intensive Care Med. 2010;36(9):1548-55.

25. Muller LM, Gorter KJ, Hak E, Goudzwaard WL, Schellevis FG, Hoepelman Al, Rutten GE. Increased risk of common infections in patients with type 1 and type 2 diabetes mellitus. Clin Infect Dis. 2005;41(3):281-8.

26. Allard R, Leclerc $P$, Tremblay $C$, Tannenbaum TN. Diabetes and the severity of pandemic influenza a (H1N1) infection. Diabetes Care. 2010;33(7):1491-3.

27. Hanslik T, Boelle PY, Flahault A. Preliminary estimation of risk factors for admission to intensive care units and for death in patients infected with a(H1N1)2009 influenza virus, France, 2009-2010. PLoS Curr. 2010;2:RRN1150.

28. Park J-E, Jung S, Kim A, Park J-E. MERS transmission and risk factors: a systematic review. BMC Public Health. 2018;18.

29. Sherbini N, Iskandrani A, Kharaba A, Khalid G, Abduljawad M, Al-Jahdali H. Middle East respiratory syndrome coronavirus in Al-Madinah City, Saudi Arabia: demographic, clinical and survival data. J Epidemiol Global Health. 2017;7(1):29.

30. Yang J, Feng Y, Yuan M, Yuan S, Fu H, Wu B, Sun G, Yang G, Zhang X, Wang L. Plasma glucose levels and diabetes are independent predictors for mortality and morbidity in patients with SARS. Diabetic Med. 2006;23(6):623.

31. Zhang J, Dong X, Cao Y, Yuan Y, Yang Y, Yan Y, Akdis C, Gao Y. Clinical characteristics of 140 patients infected by SARS-CoV-2 in Wuhan, China. Allergy. 2020.

32. Zhou F, Yu T, Du R, Fan G, Liu Y, Liu Z, Xiang J, Wang Y, Song B, Gu X. Clinical course and risk factors for mortality of adult inpatients with COVID19 in Wuhan, China: a retrospective cohort study. Lancet (London, England). 2020.

33. Guan W, Ni Z, Hu Y, Liang W, Ou C, He J, Liu L, Shan H, Lei C, Hui D. Clinical characteristics of coronavirus disease 2019 in China. N Engl J Med. 2020.

34. Wu Z, McGoogan J. Characteristics of and important lessons from the coronavirus disease 2019 (COVID-19) outbreak in China: summary of a report of 72314 cases from the Chinese Center for Disease Control and Prevention. JAMA. 2020.

35. Wu C, Chen X, Cai Y, Xia Ja, Zhou X, Xu S, Huang H, Zhang L, Zhou X, Du C. Risk Factors Associated With Acute Respiratory Distress Syndrome and Death in Patients With Coronavirus Disease 2019 Pneumonia in Wuhan, China. JAMA Internal Med. 180(7):934-43.

36. Yang J, Zheng Y, Gou X, Pu K, Chen Z, Guo Q, Ji R, Wang H, Wang Y, Zhou $Y$. Prevalence of comorbidities in the novel Wuhan coronavirus (COVID-19) infection: a systematic review and meta-analysis. Int J Infect Dis. 2020.

37. Bin S, Heo J, Song M, Lee J, Kim E, Park S, Kwon H, Kim S, Kim Y, Si Y. Environmental contamination and viral shedding in MERS patients during MERS-CoV outbreak in South Korea. Clin Infect Dis. 2016;62(6):755.

38. Arabi Y, Mandourah Y, Al-Hameed F, Sindi A, Almekhlafi G, Hussein M, Jose J, Pinto R, Al-Omari A, Kharaba A. Corticosteroid therapy for critically ill patients with Middle East respiratory syndrome. Am J Respir Crit Care Med. 2018;197(6):757

\section{Publisher's Note}

Springer Nature remains neutral with regard to jurisdictional claims in published maps and institutional affiliations.
Ready to submit your research? Choose BMC and benefit from:

- fast, convenient online submission

- thorough peer review by experienced researchers in your field

- rapid publication on acceptance

- support for research data, including large and complex data types

- gold Open Access which fosters wider collaboration and increased citations

- maximum visibility for your research: over $100 \mathrm{M}$ website views per year

At $\mathrm{BMC}$, research is always in progress.

Learn more biomedcentral.com/submissions 